\title{
Multiple-dose therapy with bovine colostrum confers significant protection against diarrhea in a mouse model of human rotavirus-induced gastrointestinal disease
}

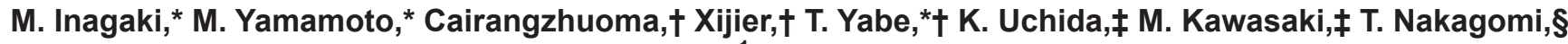 \\ O. Nakagomi, $\S$ N. Minamoto, ${ }^{*}$ and Y. Kanamaru* ${ }^{*}{ }^{1}$ \\ ${ }^{*}$ Faculty of Applied Biological Sciences, and \\ †United Graduate School of Agricultural Science, Gifu University, 1-1 Yanagido, Gifu, Gifu 501-1193, Japan \\ ¥Central R\&D Laboratory, Kobayashi Pharmaceutical Co., Ltd., 1-30-3 Toyokawa, Ibaraki, Osaka 567-0057, Japan \\ $\S$ Department of Molecular Microbiology and Immunology, Graduate School of Biomedical Sciences and Global Center of Excellence, \\ Nagasaki University, 1-12-4 Sakamoto, Nagasaki, Nagasaki 852-8523, Japan
}

\begin{abstract}
Rotavirus is the most important etiologic agent of severe gastroenteritis. Previously, we reported that skimmed and concentrated bovine late colostrum (SCBLC) obtained from normal unimmunized cows at 6 to $7 \mathrm{~d}$ after parturition effectively prevented against human rotavirus (HRV)-induced severe gastroenteritis in vivo, when administered as a single dose $60 \mathrm{~min}$ before viral inoculation. In the present study, we examined the efficacy of multiple administrations of SCBLC at smaller dosages after viral inoculation in vivo. We demonstrate that multiple administrations within $24 \mathrm{~h}$ after virus inoculation resulted in earlier recovery from diarrheal symptoms, in an administration frequencydependent manner. Furthermore, we investigated whether isolated IgG anti-HRV activity in SCBLC was equivalent to that of $\operatorname{IgG}$ isolated from bovine mature milk as measured by in vitro activity assays. We found that IgG-containing fractions from SCBLC and mature milk exhibited approximately the same level of antiHRV activity. We concluded that the SCBLC contains a high level of IgG against HRV-induced severe gastroenteritis, which will be possible to use in protective effects in immunocompromised hosts, such as children and the elderly. Multiple doses of SCBLC during the early stages of infection or lower dosage of SCBLC given as a single dose both resulted in relief of diarrheal symptoms.
\end{abstract}

Key words: bovine late colostrum, human rotavirus, multiple administrations, immunoglobulin $\mathrm{G}$

Received June 18, 2012

Accepted October 14, 2012.

${ }^{1}$ Corresponding author: kanamaru@gifu-u.ac.jp

\section{INTRODUCTION}

Human rotavirus (HRV) is the major viral enteropathogen leading to severe dehydrating gastroenteritis in infants and young children worldwide. It causes more than 527,000 deaths annually, most of which occur in developing countries (Centers for Disease Control and Prevention, 2008). To reduce the significant mortality caused by this pathogen, 2 rotavirus vaccines, RotaTeq (Merck and Co., Whitehouse station, NJ) and Rotarix (GlaxoSmithKline Biologicals, Rixensart, Belgium), have been licensed and incorporated into universal immunization programs in many countries (Centers for Disease Control and Prevention, 2008). However, first doses of both vaccines are strictly limited to infants aged between 6 and $15 \mathrm{wk}$, because of an increased risk of intussusception (Nakagomi and Nakagomi, 2009). Therefore, the development of an alternative prophylactic approach, especially non-time-limited first dose, is required for immunocompromised hosts.

Ingestion hyperimmunized colostrum has been proposed as an alternative prophylactic approach against HRV gastroenteritis (Ebina et al., 1992; Sarker et al., 1998). Hyperimmunized colostrum-containing rotavirus-specific, neutralizing IgG was produced by immunizing pregnant Holstein cows with HRV and harvesting colostrum after delivery. However, it is difficult to generate large-scale amounts of hyperimmunized colostrum. Furthermore, the sale of early colostrum from cows within $5 \mathrm{~d}$ of parturition as a food substance is illegal in Japan. Recently, we have reported that skimmed, concentrated, and pasteurized bovine milk from healthy lactating cows at 6 to $7 \mathrm{~d}$ postparturition, referred to as skimmed and concentrated bovine late colostrum (SCBLC), was effective at preventing HRV-induced diarrhea in suckling mice, indicating the potential of SCBLC to be used as a prophylactic food additive against HRV infections (Inagaki et al., 2010). 
Skimmed and concentrated bovine late colostrum has been reported to be effective in protecting against several types of viral infections (Murakami et al., 2010; Uchida et al., 2010, 2012). For example, Murakami et al. (2010) demonstrated that SCBLC reduced the binding of virus-like particles of norovirus (Ueno-7k strain) and sapovirus (NK24 strain) to human intestinal Caco2 cells in a concentration-dependent manner. Uchida et al. (2010) reported that treatments with SCBLC could shorten the duration of the disease in the upper respiratory tract caused by a virus (i.e., rhinovirus, coronavirus, and influenza virus) in clinical trials. Oral administration of SCBLC protects against influenza viral infection by activation of cellular immunity in vivo using a mouse model and in vitro using Murine Peyer's patch cells (Uchida et al., 2012). These findings support the hypothesis that ingestion of SCBLC can protect against various viral infections.

In this study, we undertook a detailed investigation of the use of SCBLC ingestion against HRV-induced diarrhea in suckling mice. Previously, multiple oral administrations per day of chemically synthesized sulfated sialyl lipid were shown to be capable of reducing the dosage per administration necessary to achieve protection against human rotavirus infection in mice (Takahashi et al., 2002). In general, a lower dosage per administration would be more acceptable for immunocompromised hosts. Furthermore, we demonstrate that anti-HRV activity of IgG is correlated with lactation stage. We previously hypothesized that the protective effect of SCBLC against HRV gastroenteritis was due to the presence of IgG as neutralizing antibody. Here, we demonstrate that SCBLC contains a larger amount of IgG than mature milk, which can bind to HRV and neutralize it.

\section{MATERIALS AND METHODS}

\section{Cells and Viruses}

African rhesus monkey MA104 cells (kidney cell line) were cultured in Eagle's minimal essential medium (MEM) supplemented with 10\% fetal calf serum (FCS). The HRV MO strain (serotype G3P[8]), HRV Wa strain (serotype G1P[8]), and bovine rotavirus NCDV strain (serotype G6P[1]) were propagated in MA104 cells and virus titer was determined by the fluorescent cell focus-forming units (FCFU) assay as described previously (Ebina et al., 1990).

\section{Materials}

All chemicals used were of reagent grade. Mouse monoclonal IgG against middle layer virus protein
(VP) 6 of the pigeon rotavirus PO-13 strain (serotype G17P[18]) used for detecting infected cells was prepared as reported previously (Minamoto et al., 1993). Fluorescein isothiocyanate-conjugated goat anti-mouse $\mathrm{IgG}$ was purchased from American Qualex (San Clemente, CA).

\section{Bovine Milk Samples}

Bovine mature milk was collected from healthy Holstein-Friesian cows held at Gifu University Farm (Gifu, Japan). The colostrum whey from a cow hyperimmunized with HRV (Rota whey) was prepared as described previously (Ebina et al., 1992). Skimmed and concentrated bovine late colostrum from normal cows was prepared at an industrial level in the facility of Kobayashi Pharmaceuticals (Osaka, Japan; Inagaki et al., 2010). Briefly, the pooled late colostrum from healthy cows at 6 to $7 \mathrm{~d}$ after delivery was defatted by centrifugation, pasteurized via HTST conditions (at $73^{\circ} \mathrm{C}$ for $15 \mathrm{~s}$ ), and then concentrated by ultrafiltration and spray dried. The milk protein concentration was determined with a Bradford protein assay kit (Bio-Rad Laboratories Inc., Hercules, CA) using BSA as standard following the manufacturer's instructions.

\section{Protein G Affinity Chromatography}

After removal of casein by acid precipitation $(\mathrm{pH}$ 4.6), whey protein was dissolved in $20 \mathrm{~m} M$ sodium phosphate buffer ( $\mathrm{pH} 7.0$ ) at a concentration of $5 \mathrm{mg} /$ $\mathrm{mL}$. Affinity chromatography was performed using a HiTrap Protein G HP (5 mL; GE Healthcare, Chalfont St. Giles, UK) column equilibrated with the same buffer, connected with and controlled by an ÄKTA prime system (GE Healthcare). Whey was loaded onto the column at a flow rate of $5 \mathrm{~mL} / \mathrm{min}$. Elution of bound proteins was performed using an elution buffer $(0.1 \mathrm{M}$ Glycine-HCl buffer, $\mathrm{pH}$ 2.7). Each 2-mL fraction was monitored via spectrophotometry at $280 \mathrm{~nm}$ for protein content. Fractions containing eluted IgG fractions were neutralized with $1 \mathrm{M}$ Tris- $\mathrm{HCl}(\mathrm{pH} 9.0)$, and freeze dried after dialysis against distilled water.

\section{Mouse Diarrhea Model}

We used a previously developed mouse model of rotavirus gastroenteritis to study protective efficacy in the development of diarrhea (Ebina et al., 1990). Mice (BALB/c), $14 \mathrm{~d}$ pregnant, were purchased from Japan SLC (Hamamatsu, Japan) and gave birth several days later. Litters of 5 -d-old mice (the average BW was 3.4 g) were orally inoculated with a single dose of $1.7 \times$ $10^{5} \mathrm{FCFU} / 50 \mu \mathrm{L}$ of HRV MO strain by gavage. Stools 
were examined daily, every $24 \mathrm{~h}$ after virus inoculation, for the development of diarrhea by gently pressing and massaging the abdomen beginning at $1 \mathrm{~d}$ postinoculation for $4 \mathrm{~d}$. A 3-point ranking system (diarrhea index, DI) was used to characterize diarrhea (Takahashi et al., 2002): 1 = normal brown formed stool or no stool, $2=$ soft orange stool, and $3=$ liquid yellow stool. Skimmed and concentrated bovine late colostrum was dissolved in $50 \mu \mathrm{L}$ of PBS and then given orally to suckling mice in the experimental group by gavage, 60 min before viral inoculation. Control mice were given only PBS (pH 7.2). Diarrhea scores were calculated by average of diary stool observations. The care and experimental procedures were approved by the Animal Care and Use Committee of Gifu University.

\section{Rotavirus Replication Inhibition (Neutralization) Assay}

The replication inhibition assay for the HRV MO strain was carried out using MA104 cells as described previously (Ebina et al., 1990). A suspension containing infectious virus at a titer of $10^{5}$ to $10^{6} \mathrm{FCFU} / \mathrm{mL}$ was treated with $10 \mu \mathrm{g} / \mathrm{mL}$ of trypsin (Sigma-Aldrich, St. Louis, MO) for $30 \mathrm{~min}$ at $37^{\circ} \mathrm{C}$. After appropriate dilution with MEM containing 10\% FCS to give a titer of approximately $4 \times 10^{3}$ FCFU per $100 \mu \mathrm{L}$, aliquots were serially diluted 1:1 with MEM containing 10\% FCS; samples were then incubated in microtubes for $1 \mathrm{~h}$ at $37^{\circ} \mathrm{C}$. The diluted mixtures were then used to inoculate MA104 cells $\left(2 \times 10^{5}\right.$ cells $\left./ \mathrm{mL}, 200 \mu \mathrm{L}\right)$; in addition, $20-\mu \mathrm{L}$ aliquots of each were placed into the wells of a 24-well heavy Teflon-coated slide (AR Brown Co. Ltd., Tokyo, Japan). Control cells gave about 100 infected foci per well and replaced milk samples with MEM containing 10\% FCS. The cells were further cultured for $22 \mathrm{~h}$ at $37^{\circ} \mathrm{C}$ under an atmosphere of $5 \%$ $\mathrm{CO}_{2}$ and then fixed with cold acetone for $20 \mathrm{~min}$. The number of foci in wells containing infected cells was measured using an indirect immunofluorescence assay using a monoclonal antibody against VP6 of pigeon rotavirus PO-13 (Minamoto et al., 1993) and fluorescein isothiocyanate-conjugated anti-mouse IgG goat serum. Neutralizing activity was expressed as percentage reduction in the foci number of infected cells observed by fluorescence microscopy. The MIC (the minimum concentration showing a 50\% reduction of infected cells) was calculated for each sample from a logarithmic regression of the concentration-dependent percentage of foci reduction.

\section{HRV-Binding Radio Immunoprecipitation Assay}

A virus-binding radio immunoprecipitation assay (RIPA) was performed with radiolabeled HRV Wa and bovine rotavirus NCDV strains. Confluent, Wa straininfected MA104 cells were radiolabeled with $3,700 \mathrm{kBq}$ of ${ }^{35} \mathrm{~S}$-methionine for $2 \mathrm{~h}$ at $37^{\circ} \mathrm{C}$ under an atmosphere of $5 \% \mathrm{CO}_{2}$. After washing with cold PBS 3 times, cells were incubated with RIPA buffer $(50 \mathrm{~m} M$ Tris, 150 $\mathrm{m} M$ sodium chloride, $1 \mathrm{~m} M$ EDTA, $1.0 \%$ Triton-X, $0.5 \%$ sodium deoxycholate, $10 \mu \mathrm{g} / \mathrm{mL}$ aprotinin, and $0.02 \mathrm{~m} M$ phenylmethylsulfonyl fluoride, $\mathrm{pH} 8.0$ ) for 15 min on ice, and homogenized. The homogenized solution was then centrifuged at $13,200 \times g$ for $1 \mathrm{~min}$; the resulting supernatants were used as radiolabeled virus.

Bovine colostrum IgG in PBS was mixed by vortex with $10 \mu \mathrm{L}$ of radiolabeled virus in microtubes at room temperature. After the addition of protein G-Sepharose [protein G-Sepharose:RIPA buffer = 1:1 ( vol/vol); GE Healthcare], the microtube was incubated for $1 \mathrm{~h}$ on ice. The IgG-protein G-Sepharose complex was collected by centrifugation at $13,200 \times g$ for a few seconds and washed with RIPA buffer 3 times, followed by 1 wash with PBS.

Sodium dodecyl sulfate PAGE was performed using the Laemmli method (Laemmli, 1970). The IgGprotein G-Sepharose complexes were boiled for $3 \mathrm{~min}$ in SDS-PAGE sample buffer in the presence of 2-mercaptoethanol. After centrifugation, the supernatants were subjected to SDS-PAGE. After separation of the proteins, the gel was fixed and then immersed in $1 \mathrm{M}$ sodium salicylate. After soaking in $5 \%$ glycerol, the gel was dried. Imaging was performed on a bio-imaging analyzer (FUJIX BAS-2000; Fujifilm, Tokyo, Japan).

\section{Statistical Analysis}

Statistical analysis of the mice diarrhea experiments were performed using the Mann-Whitney U test. Analysis of variance was used to examine the difference between SCBLC and PBS. Significance was set at $P$ $<0.05$. Data in the text are means \pm standard deviation. Statistical analysis of in vitro experiments were performed using Welch's $t$-test.

\section{RESULTS}

\section{Gastroenteritis Caused by HRV in Suckling Mice}

Initially, we examined HRV titer required for the induction of gastroenteritis symptoms in suckling mice. Litters of 5-d-old BALB/c mice were orally inoculated with 3 different titers of the HRV MO strain in $50 \mu \mathrm{L}$ $\left(1.7 \times 10^{5}, 8.5 \times 10^{4}\right.$, and $4.2 \times 10^{4} \mathrm{FCFU}$, respectively) via a single administration. Control mice received the equivalent volume of PBS. Mice were inspected for characteristics of diarrhea by gentle palpation of the abdomen at $48 \mathrm{~h}$ postinoculation (hpi); HRV-induced 
Table 1. Diarrhea in mice following oral infection with human rotavirus MO strain at $48 \mathrm{~h}$ postinoculation

\begin{tabular}{|c|c|c|c|c|}
\hline \multirow[b]{2}{*}{ Dosage $^{1}$} & \multirow[b]{2}{*}{ Litter } & \multirow[b]{2}{*}{$\begin{array}{l}\text { No. of } \\
\text { mice }\end{array}$} & \multicolumn{2}{|c|}{ Diarrhea } \\
\hline & & & $\begin{array}{l}\text { No. of } \\
\text { mice }\end{array}$ & Percent \\
\hline 0 & $\mathrm{~A}$ & 7 & 0 & 0 \\
\hline $1.7 \times 10^{5}$ & $\begin{array}{l}\mathrm{C} \\
\mathrm{C} \\
\mathrm{D}\end{array}$ & $\begin{array}{l}7 \\
7 \\
5\end{array}$ & $\begin{array}{l}7 \\
4\end{array}$ & 91.7 \\
\hline $8.5 \times 10^{4}$ & $\begin{array}{l}\mathrm{E} \\
\mathrm{F}\end{array}$ & $\begin{array}{l}6 \\
6\end{array}$ & $\begin{array}{l}6 \\
5\end{array}$ & 91.7 \\
\hline $4.3 \times 10^{4}$ & $\begin{array}{l}\mathrm{G} \\
\mathrm{H}\end{array}$ & $\begin{array}{l}6 \\
6\end{array}$ & $\begin{array}{l}5 \\
5\end{array}$ & 83.3 \\
\hline
\end{tabular}

${ }^{1}$ Fluorescent cell focus-forming units (FCFU)/mouse.

diarrhea symptoms in the suckling mouse model were the most overt at 48 hpi (Ebina et al., 1990).

As shown in Table 1, mock-infected control mice exhibited no diarrheal symptoms, whereas the majority of mice inoculated with HRV had severe diarrhea, regardless of viral titer. However, we observed that the viral titer of $4.3 \times 10^{4} \mathrm{FCFU} /$ mouse led to a decreased incidence of diarrhea. We adopted the highest viral titer of $1.7 \times 10^{5} \mathrm{FCFU} /$ mouse to ensure that diarrhea was induced.

\section{The Protective Efficacy of SCBLC by a Single Administration Against HRV-Induced Diarrhea in Suckling Mice}

To assess the effective dosage of SCBLC for prevention of HRV-induced diarrhea by a single administration, litters of 5-d-old suckling mice were orally given $0.1,1.0$, or $2.5 \mathrm{mg}$ of SCBLC in $50 \mu \mathrm{L}$ of PBS $60 \mathrm{~min}$ before inoculation with the HRV MO strain. Control mice were given $50 \mu \mathrm{L}$ of PBS. The DI was calculated as an average of diary stool observations.

As shown in Figure 1, in the control group, we observed that 9 of the 13 mice presented with diarrhea at $48 \mathrm{hpi}(\mathrm{DI}=2.38 \pm 0.90)$ and a few still suffered from diarrhea at $96 \mathrm{hpi}(\mathrm{DI}=2.00 \pm 0.67)$. Conversely, in the group that received $2.5 \mathrm{mg}$ of SCBLC, only 1 of 11 mice developed diarrhea at $48 \mathrm{hpi}(\mathrm{DI}=1.27$ \pm 0.65 ). Similarly, in the group receiving $1.0 \mathrm{mg}$ of SCBLC, only 1 of 6 mice developed diarrhea and half of mice presented with soft orange stool at $48 \mathrm{hpi}$ (DI, $=1.83 \pm 0.75)$. Almost half of the mice given $0.1 \mathrm{mg}$ of SCBLC suffered from diarrhea at $48 \mathrm{hpi}(\mathrm{DI}=2.00 \pm$ 1.05). Although all mice recovered from the diarrhea, most of the mice suffered from soft brown stool at 96 hpi (DI $=1.80 \pm 0.42$ ). Therefore, we found that a single administration of $2.5 \mathrm{mg}$ of SCBLC significantly protected against HRV-induced diarrhea, whereas 0.1 mg of SCBLC did not have a statistically significant effects on it by a single administration.
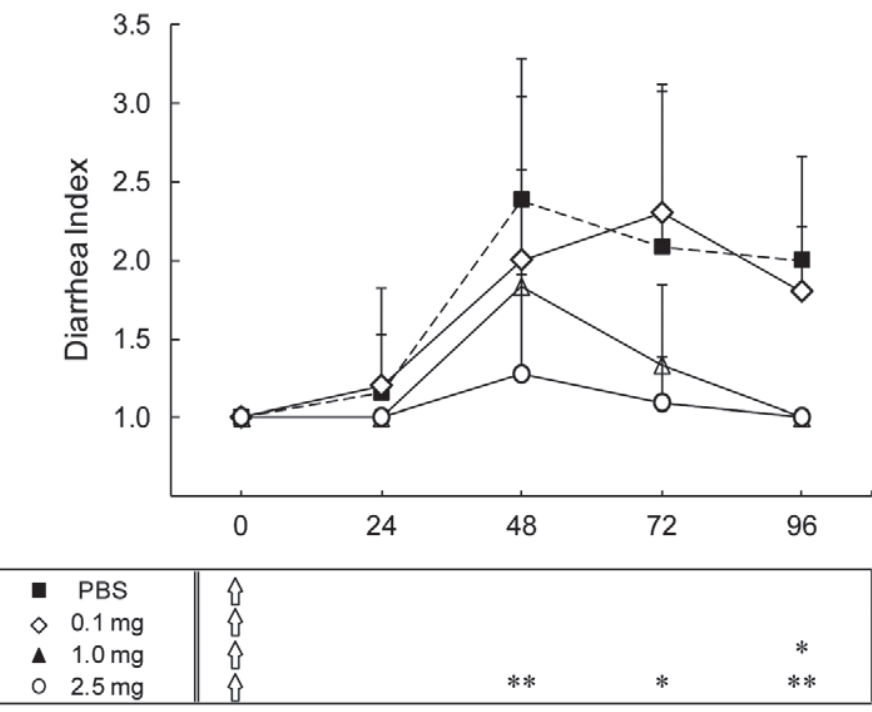

Hours postinoculation

Figure 1. Effect of different dosages of skimmed and concentrated bovine late colostrum (SCBLC) against human rotavirus (HRV)induced diarrhea in suckling mice. Litters of 5-d-old mice were orally given either PBS ( $\mathrm{n}=13$, solid squares with dotted line) or SCBLC for 60 min before viral inoculation with $1.7 \times 10^{5}$ fluorescent cell focusforming units (FCFU) of HRV MO strain per mouse. The treatment groups were $2.5 \mathrm{mg}$ of SCBLC group ( $\mathrm{n}=11$, open circles), $1.0 \mathrm{mg}$ of SCBLC group ( $\mathrm{n}=8$, solid triangles), and $0.1 \mathrm{mg}$ of SCBLC group (n $=10$, open diamonds). Stools were examined daily to assess diarrhea from 0 to $96 \mathrm{~h}$ postinoculation (hpi) and diarrhea was characterized using a diarrhea index (DI), where $1=$ normal brown formed stool or no stool, $2=$ soft orange stool, and $3=$ liquid yellow stool. Each point represents the mean $\pm \mathrm{SD}$. Open arrows in the box under the figure indicate the timing of SCBLC administration, starting $60 \mathrm{~min}$ before viral inoculation. Asterisks indicate the degree of statistical significance versus the control at each time point: ${ }^{*} P<0.05$ and ${ }^{* *} P$ $<0.01$, as determined by the Mann-Whitney $\mathrm{U}$ test.

\section{The Effect of Administration Frequency of SCBLC Against HRV-Induced Diarrhea}

To evaluate the effect of administration frequency in lower-dose multiple administrations of SCBLC, we used the $0.1-\mathrm{mg}$, nonprotective dosage, as shown in Figure 1. Three different administration interval schemes are indicated by an arrow in the box in Figure 2. The first dose was given orally 60 min before viral inoculation. Additional doses were given orally by gavage $3(24,48$, and $72 \mathrm{hpi}), 4(12,24,48$, and $72 \mathrm{hpi})$, or $5(6,12,24$, 48 , and $72 \mathrm{hpi}$ ) times after viral inoculation. Control mice were given PBS by gavage 5 times. The DI was calculated as an average of diary stool observations.

As shown in Figure 2, in the control group, all 9 of the mice developed diarrhea at $48 \mathrm{hpi}$ (DI $=3.00 \pm$ $0.00)$, with more than half still presenting with soft orange stool at $96 \mathrm{hpi}(\mathrm{DI}=1.57 \pm 0.53)$. In comparison, in the SCBLC groups, we observed that all mice given SCBLC presented similar diarrheal symptom levels un- 


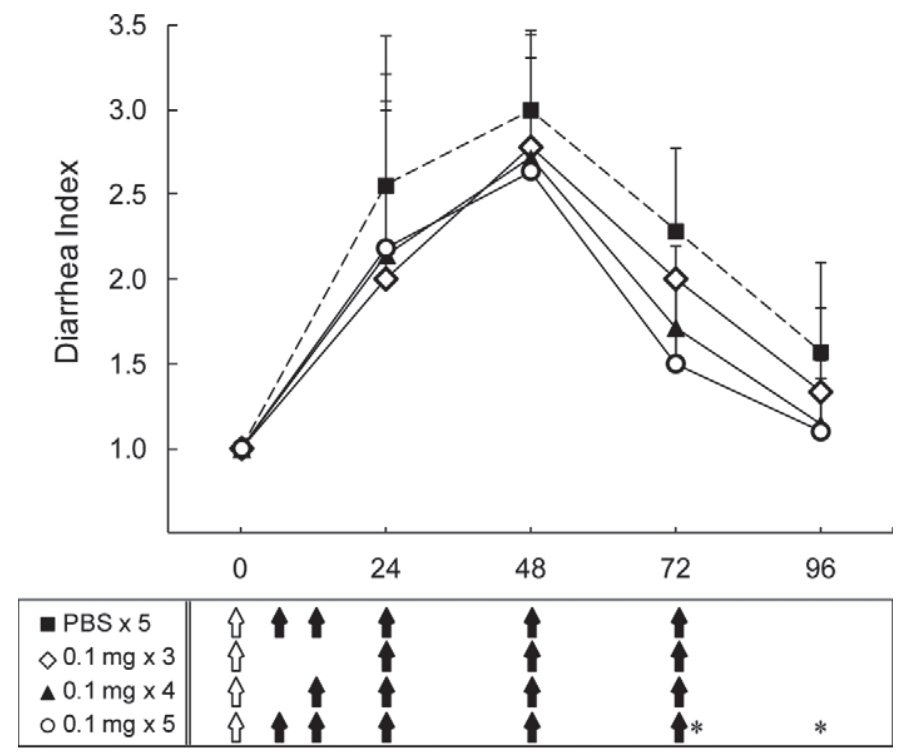

Hours postinoculation

Figure 2. Effect of skimmed and concentrated bovine late colostrum (SCBLC) given at various dosage intervals against human rotavirus (HRV)-induced diarrhea in suckling mice. Litters of 5-d-old mice were orally given either PBS ( $\mathrm{n}=9$, solid squares with dotted line) or $0.1 \mathrm{mg}$ of SCBLC for $60 \mathrm{~min}$ before viral inoculation with $1.7 \times 10^{5}$ fluorescent cell focus-forming units (FCFU) of HRV MO strain per mouse. After viral inoculation, additional doses of $0.1 \mathrm{mg}$ of SCBLC in $50 \mu \mathrm{L}$ of PBS were administered orally by gavage 3 times [24, 48, and $72 \mathrm{~h}$ postinoculation (hpi), $\mathrm{n}=9$, open diamonds], 4 times (12, 24, 48, and $72 \mathrm{hpi}, \mathrm{n}=7$, solid triangles), or 5 times $(6,12,24,48$, and $72 \mathrm{hpi}, \mathrm{n}=11$, open circles). Control mice were given PBS by gavage 5 times. Stools were examined daily to assess diarrhea from 0 to $96 \mathrm{hpi}$ and diarrhea was characterized using a diarrhea index (DI), where $1=$ normal brown formed stool or no stool, $2=$ soft orange stool, and 3 = liquid yellow stool. Each point represents the mean \pm $\mathrm{SD}$. Open arrows in the box under the figure indicate the time points at which each dose of SCBLC was administered, starting 60 min before viral inoculation. Closed arrows indicate the time points at which each dose of SCBLC was administered after viral inoculation. ${ }^{*} P<0.05$, as determined by the Mann-Whitney U test.

til 48 hpi (DI $=2.00-2.18)$ and then experienced a mild reduction in symptoms in an administration frequencydependent manner from $72 \mathrm{hpi}$ onward. The group receiving 5 administrations of SCBLC experienced a significant reduction of symptoms at $72 \mathrm{hpi}(\mathrm{DI}=1.50$ $\pm 0.53, P=0.015)$ and $96 \mathrm{hpi}(\mathrm{DI}=1.10 \pm 0.32, P=$ 0.048 ), indicating that the administration frequency of SCBLC within the first $24 \mathrm{hpi}$ is important for relieving diarrheal symptoms.

\section{The Effects of Varying Doses of SCBLC Against HRV-Induced Diarrhea}

To evaluate the minimum effective dosage given over multiple administrations that was effective in reducing diarrheal symptoms, we investigated 3 different dosage amounts of SCBLC $(0.1,0.2$, and $0.3 \mathrm{mg})$. We gave a single administration of SCBLC before viral inoculation, followed by 3 administrations within 24 hpi (60 min before viral inoculation, and 6, 12, and $24 \mathrm{hpi}$ ). Control mice were given PBS with same administration schedule. Diarrhea scores were calculated as an average of daily stool observations.

As shown in Figure 3, in the PBS group, all 6 mice developed diarrhea at $48 \mathrm{hpi}(\mathrm{DI}=3.00 \pm 0.00)$ and thereafter most of the mice presented soft brown stool until 96 hpi $(\mathrm{DI}=1.83 \pm 0.41)$. At the 0.1 and 0.2 $\mathrm{mg}$ doses, similar symptom levels $(\mathrm{DI}=2.78 \pm 0.67)$ were observed at $48 \mathrm{hpi}$, followed by symptom levels of $1.67 \pm 0.50$ and $1.75 \pm 0.46$ at $96 \mathrm{hpi}$, respectively. In contrast, at the $0.3 \mathrm{mg}$ dosage, 7 of 9 mice presented a DI of 1 or 2 at 48 hpi (DI $=2.11 \pm 0.60)$, all mice recovered from severe diarrhea at $72 \mathrm{hpi}(\mathrm{DI}=1.78 \pm$ 0.44 ), and finally, the DI at $96 \mathrm{hpi}$ was reduced to 1.22 \pm 0.44 . These results indicate that a minimum effective dosage of $0.3 \mathrm{mg}$ of SCBLC over multiple administrations within 24 hpi is necessary to relieve HRV-induced diarrhea in suckling mice.

\section{Multiple Administration Effects of SCBLC Against HRV-Induced Diarrhea in Suckling Mice}

The effectiveness of the 0.1-mg dose of SCBLC over multiple administrations was analyzed in detail, as shown in Figure 4. Panel A is a summary of symptomatic diarrhea after three $0.1-\mathrm{mg}$ administrations every $24 \mathrm{~h}$ after viral inoculation (adapted from Figure 2). All 9 mice presented soft orange stool (DI of 2) at $72 \mathrm{hpi}$, after which only 3 of 9 still had soft stool symptoms. Panel B shows a summary of symptomatic diarrhea after three 0.1-mg administrations within $24 \mathrm{~h}$ after viral inoculation (adapted from Figure 3 ). Five of 9 mice developed liquid yellow diarrhea (DI of 3 ) at 72 hpi; 6 of 9 mice still presented soft orange stool (DI of 2) at 96 hpi. Panel C shows a summary of symptomatic diarrhea after five 0.1-mg administrations every $24 \mathrm{~h}$ after viral inoculation: 3 administrations within 24 hpi and 2 administrations from 24 hpi onward (adapted from Figure 2). Half of the 10 mice developed soft orange diarrhea (DI of 2) at $72 \mathrm{hpi}$ and then 9 of 10 mice recovered by 96 hpi.

Comparison of the scheme presented in panel A with that in panel $\mathrm{C}$ of Figure 4 suggests that multiple administrations within 24 hpi can relieve diarrheal symptoms from 48 hpi onward. Furthermore, comparison of the scheme presented in panel $\mathrm{B}$ with that in panel C suggests that repetitive administrations from $24 \mathrm{hpi}$ onward are important for early recovery against HRVinduced diarrhea. 

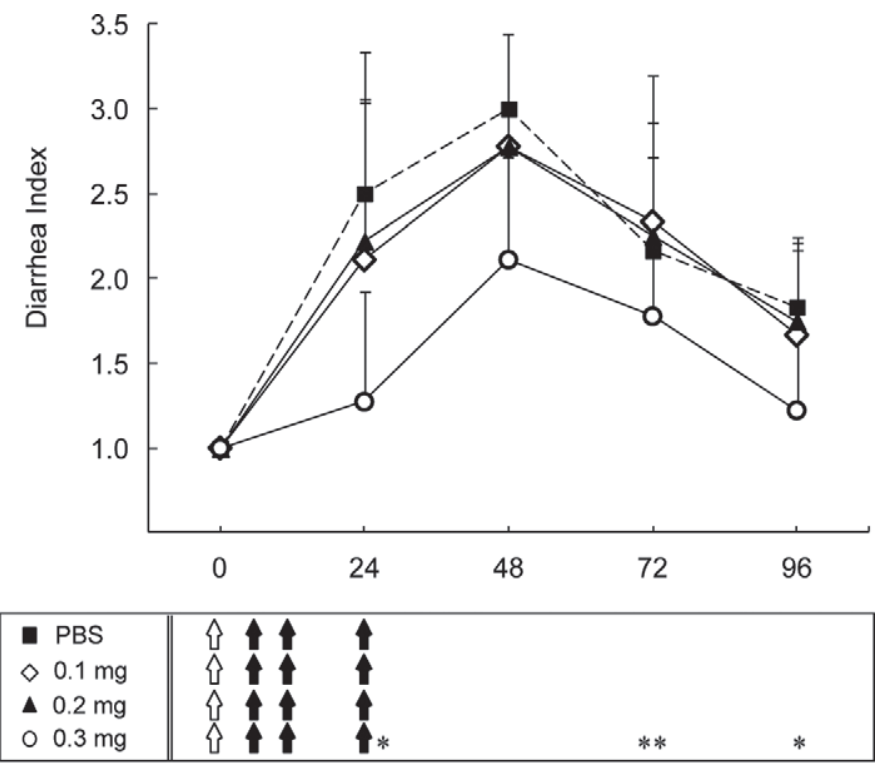

Hours postinoculation

Figure 3. Effect of multiple administrations of varying doses of skimmed and concentrated bovine late colostrum (SCBLC) against human rotavirus (HRV)-induced diarrhea in suckling mice. Litters of 5 -d-old mice were orally given either PBS $(\mathrm{n}=6$, solid squares with dotted line) or SCBLC for 60 min before viral inoculation with $1.7 \times$ $10^{5}$ fluorescent cell focus-forming units (FCFU) of HRV MO strain per mouse. After viral inoculation, SCBLC was orally given by gavage 5 times $[6,12,24,48$, and $72 \mathrm{~h}$ postinoculation (hpi)]. The dosages tested were $0.1 \mathrm{mg}$ ( $\mathrm{n}=9$, open diamonds), $0.2 \mathrm{mg}(\mathrm{n}=9$, solid triangles), and $0.3 \mathrm{mg}(\mathrm{n}=11$, open circles). Stools were examined daily to assess diarrhea from 0 to $96 \mathrm{hpi}$ and diarrhea was characterized using a diarrhea index (DI), where $1=$ normal brown formed stool or no stool, 2 $=$ soft orange stool, and $3=$ liquid yellow stool. Each point represents the mean $\pm \mathrm{SD}$. Open arrows in the box under the figure indicate the time points at which each dose of SCBLC was administered before viral inoculation. Closed arrows indicate the time points at which each dose of SCBLC was administered after viral inoculation. ${ }^{*} P<0.05$ and ${ }^{* *} P<0.01$, as determined by the Mann-Whitney $\mathrm{U}$ test.

\section{Anti-HRV Activity in IgG-Containing Fractions of SCBLC and Mature Milk}

Skimmed and concentrated bovine late colostrum contains large amounts of immunoglobulins. To compare the ability of IgG from SCBLC and mature milk to reduce HRV-induced diarrheal symptoms, we isolated and examined purified IgG from both SCBLC and mature milk. IgG was isolated using an affinity chromatography protein $\mathrm{G}$ column. Confirmation of the $\mathrm{IgG}$ isolated was performed using 2-dimensional PAGE, and heavy and light chains of IgG were detected by Coomassie Brilliant Blue (data not shown).

As shown in Figure 5, SCBLC exhibited an inhibitory activity against HRV with an MIC of $2.1 \mu \mathrm{g} / \mathrm{mL}$. By contrast, the MIC of mature milk was approximately $200 \mu \mathrm{g} / \mathrm{mL}$, which was 100 times weaker than that of SCBLC. Isolated IgG from SCBLC showed strong inhibitory activity against HRV with an MIC of 0.43
A
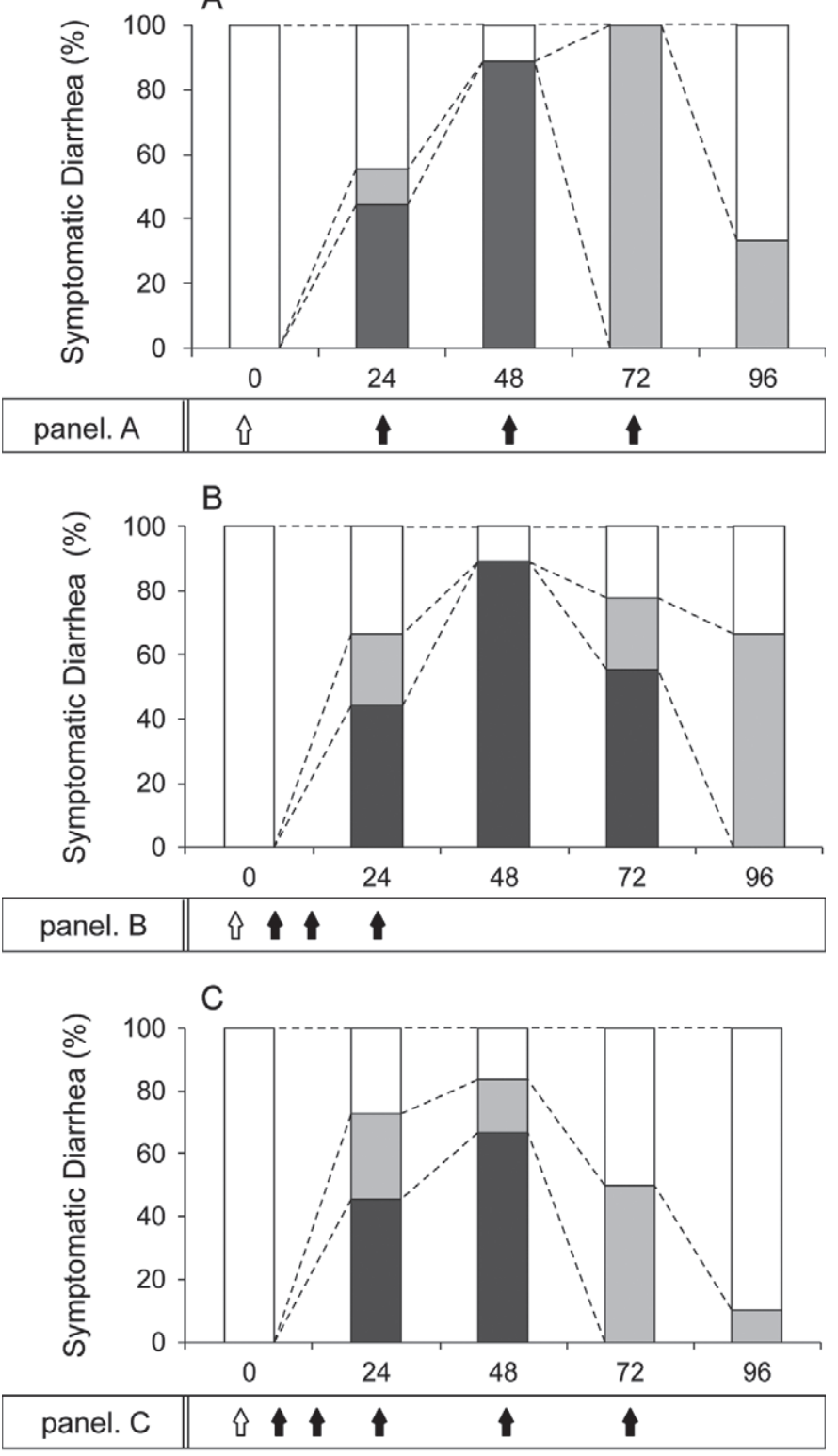

Hours postinoculation

Figure 4. Summary of diarrhea symptoms in suckling mice infected with human rotavirus (HRV) MO strain after multiple administrations of $0.1 \mathrm{mg}$ of skimmed and concentrated bovine late colostrum (SCBLC). Litters of 5-d-old mice were given $0.1 \mathrm{mg}$ of SCBLC orally for 60 min before viral inoculation with $1.7 \times 10^{5}$ fluorescent cell focusforming units (FCFU) of HRV MO strain per mouse (open arrow). In panel A, SCBLC was given orally by gavage 3 times at 24,48 , and 72 $\mathrm{h}$ postinoculation (hpi). In panel B, SCBLC was given orally by gavage 3 times at 6,12 , and $24 \mathrm{hpi}$. In panel C, SCBLC was given orally by gavage 5 times at $6,12,24,48$, and 72 hpi. Symptomatic diarrhea is expressed as the percentage of mice presenting diarrhea compared with total mice (100\%): diarrhea index (DI) $1=$ normal brown formed stool or no stool (open box), DI 2 = soft brown stool (gray box), and DI 3 $=$ liquid yellow stool (black box). 
$\mu \mathrm{g} / \mathrm{mL}$. Remarkably, the MIC of IgG from mature milk was $0.74 \mu \mathrm{g} / \mathrm{mL}$, which was similar to the inhibitory activity of IgG from SCBLC. Therefore, the anti-HRV activity of SCBLC is dependent on the concentration of IgG present in the sample.

\section{Bovine Colostrum IgG Bound to Human and Bovine Rotavirus Protein}

To determine the rotavirus structural proteins recognized by bovine colostrum IgG, radiolabeled rotavirus and IgG were mixed and IgG was collected by RIPA using protein G-Sepharose. The obtained IgG-protein G-Sepharose was analyzed by SDS-PAGE. As shown in Figure 6, the radiolabeled HRV (Wa strain) gave 3 major bands of almost 83, 48, and $33 \mathrm{kDa}$. These bands were likely the outer capsid spike VP4, the middle

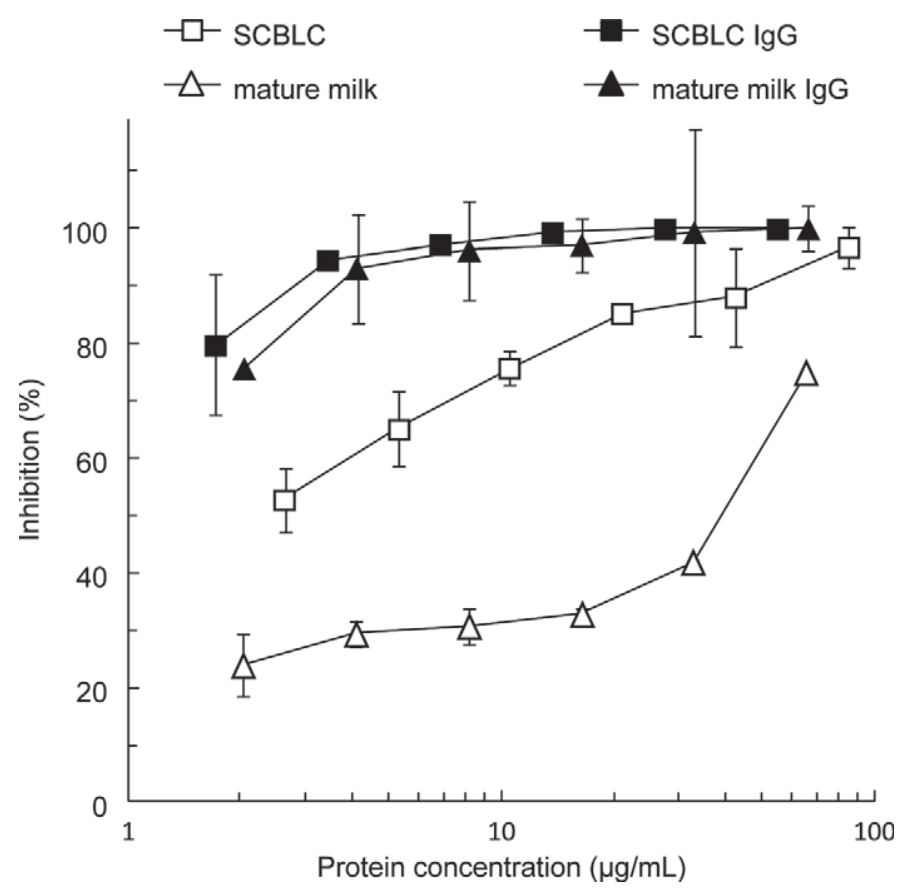

Figure 5. Comparison of the anti-human rotavirus (HRV) effects of IgG fractions from skimmed and concentrated bovine late colostrum (SCBLC) and mature milk. The HRV MO strain was incubated with each of the samples for 60 min before inoculation. The virus-sample mixture was then added to African rhesus monkey MA104 cells (kidney cell line) and the mixture was then incubated under a $5 \% \mathrm{CO}_{2}$ atmosphere at $37^{\circ} \mathrm{C}$ for a further $22 \mathrm{~h}$. Control cells were prepared in the same way, except that preincubation occurred in the presence of Eagle's minimal essential medium (MEM) containing 10\% fetal calf serum (FCS). Concentrations of the samples are given on a logarithmic scale: SCBLC (open squares), IgG from SCBLC (SCBLC IgG, closed squares), mature milk (open triangles), and IgG from mature milk (mature milk IgG, closed triangles). The inhibitory activity of each sample is expressed as the percentage of infected cells compared with control cells $(100 \%)$. The experiments were carried out in triplicate at least 3 times, and representative results for each sample are given as means $\pm \mathrm{SD}$

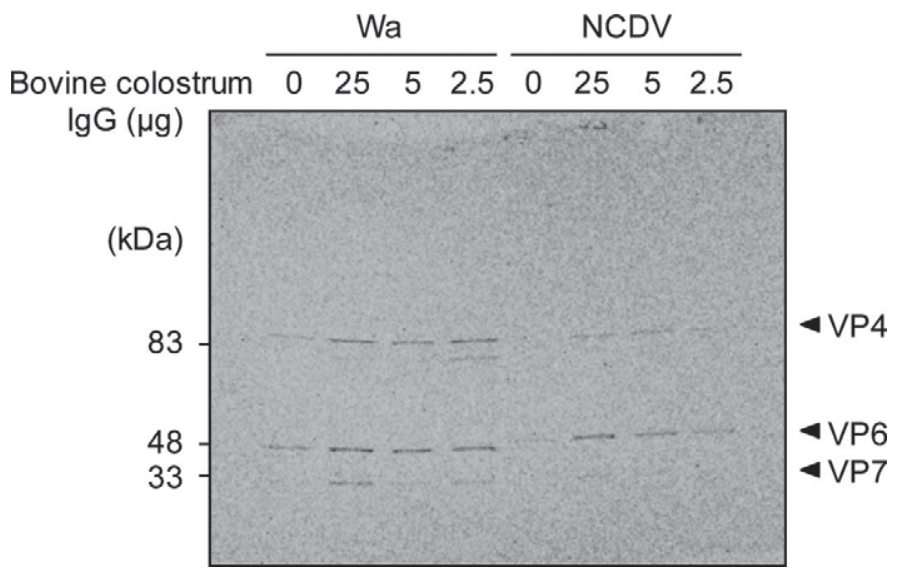

Figure 6. Analysis of rotavirus structural proteins recognized by bovine colostrum IgG. Immunoglobulin G from normal bovine colostrum was incubated with ${ }^{35} \mathrm{~S}$-labeled rotavirus. The virus-IgG mixture was purified using protein G-Sepharose, and then subjected to SDS-PAGE on a 5 to $15 \%$ gradient gel. Imaging was performed on a Bio-imaging analyzer (FUJIX BAS-2000; Fujifilm, Tokyo, Japan). $\mathrm{Wa}=$ human rotavirus Wa strain (serotype G1P[8]); NCDV = bovine rotavirus NCDV strain (serotype $\mathrm{G} 6 \mathrm{P}[1]$ ); $\mathrm{VP}=$ virus protein.

layer VP6, and the smooth surface glycoprotein VP7, respectively (Estes and Cohen, 1989). In the case of bovine rotavirus (NCDV strain), similar band patterns were detected (Figure 6). Because these are all proteins located in the outer capsid of the virus, we concluded that bovine IgG protects against rotavirus infection by neutralizing the virus.

\section{DISCUSSION}

In this study, we compared the ability of IgG derived from SCBLC and mature milk to inhibit HRV-induced diarrhea. Although immunoglobulin levels in cow milk are predicted to decline throughout the duration of lactation, the anti-HRV activity of IgG appeared to hold regardless of the length of lactation (Figure 5). Furthermore, bovine colostrum IgG binding to rotavirus was detected using RIPA (Figure 6). Although the efficacy of hyperimmunized bovine colostrum against HRV was demonstrated in clinical trials of children (Ebina et al., 1992; Sarker et al., 1998), its actual use has been limited because of difficulties in large-scale production. Thus, unimmunized SCBLC produced from normal healthy cows may provide an alternative option for the prevention and management of severe rotavirus diarrhea in immunocompromised children.

Furthermore, we demonstrated that multiple administrations of SCBLC could protect against symptoms of HRV infection in suckling mice. First, we confirmed that a prophylactic, oral, single administration of SCBLC, at a dosage greater than $1.0 \mathrm{mg}, 60 \mathrm{~min}$ before viral inoculation, prevented the development of diar- 
rhea (Figure 1). Second, we examined the effect of altering the administration frequency of SCBLC against HRV-induced diarrhea. Five administrations of SCBLC after viral inoculation $(6,12,24,48$, and $72 \mathrm{hpi})$ at a dosage of $0.1 \mathrm{mg}$ was as effective as a greater dosage administered fewer times (i.e., prophylactic single administration) and did have the potential of reducing development of diarrhea (Figure 2). These results also indicated that recovery of diarrheal symptoms was relevant to the frequency of administrations after virus inoculation, especially within $24 \mathrm{hpi}$ (Figure $4 \mathrm{~A}$ and $4 \mathrm{C})$. Additionally, we concluded the minimum effective dosage over multiple administrations within 24 hpi was $0.3 \mathrm{mg}$ (Figure 3).

Interestingly, Guarino et al. (1996) reported that serum immunoglobulin was effective against rotavirus infection in a Caco-2 cell monolayer model. In their in vitro experiments using transepithelial electrical resistance (TER), they showed that the addition of immunoglobulin to rotavirus-infected cells promoted restoration of the monolayer's integrity. Serum immunoglobulin was effective in a time- and dosage-dependent manner. Hence, our in vivo results are in good agreement with the in vitro findings of Guarino et al. (1996), emphasizing the importance of early treatment against HRV infection.

Previous studies indicated that rotavirus infection of Caco-2 cells caused disruption of tight junctions and loss of TER before the cell death (Svensson et al., 1991; Dickman et al., 2000; Obert et al., 2000; Ciarlet et al. 2001; Catto-Smith et al., 2008). From 2000 onward, rotavirus infection contributed significantly to alterations in the distribution of tight junction proteins [occludin (Obert et al., 2000; Dickman et al., 2000; Beau et al.,2007), claudin-1 (Dickman et al., 2000), and ZO-1 (Dickman et al., 2000)] in Caco-2 cells. These findings suggest that defense against the disruption of tight junctions is one of the mechanisms by which to relieve diarrheal symptoms. Another remarkable observation was multiple administrations from 24 hpi onward resulted in earlier recovery from HRV-induced diarrhea (Figure $4 \mathrm{~B}$ and $4 \mathrm{C}$ ). We previously observed that SCBLC has preventive and healing effects on intestinal injury induced by nonsteroidal, antiinflammatory drugs, such as indomethacin (Cairangzhuoma et al., 2013).

\section{CONCLUSIONS}

Taken together, SCBLC is effective at reducing the severity of HRV infection compared with mature milk in vitro; this effectiveness is not attributable to the antiviral titer of $\operatorname{IgG}$ but quantity of $\operatorname{IgG}$, regardless of lactation period. In the suckling mouse model, we found that multiple administrations with a lower dos- age of SCBLC relieved the HRV-induced diarrheal symptoms and concluded that a key to the relieving diarrheal symptoms was administration of the minimum effective dosage of SCBLC as early as possible coupled with repetitive intake in the duration of diarrhea. Skimmed and concentrated bovine late colostrum will offer promising natural treatment options against HRV infections.

\section{ACKNOWLEDGMENTS}

We express our thanks to Y. Yamada (Faculty of Applied Biological Sciences, Gifu University, Gifu, Japan) for helpful technical assistance. This research was supported by the Japan Society for the Promotion of Science [JSPS, Tokyo, Japan; Grant-in-Aid for Scientific Research (C) no. 21580325 (to Y. Kanamaru)].

\section{REFERENCES}

Beau, I., J. Cotte-Laffitte, R. Amsellem, and A. L. Servin. 2007. A protein kinase A-dependent mechanism by which rotavirus affects the distribution and mRNA level of the functional tight junctionassociated protein, occludin, in human differentiated intestinal Caco-2 cells. J. Virol. 81:8579-8586.

Cairangzhuoma, , M. Yamamoto, H. Muranishi, M. Inagaki, K. Uchida, K. Yamashita, S. Saito, T. Yabe, and Y. Kanamaru. 2013. Skimmed, sterilized, and concentrated bovine late colostrum promotes both prevention and recovery from intestinal damage in mice. J. Dairy Sci. http://dx.doi.org/10.3168/jds.2012-5701. (Accepted.)

Catto-Smith, A. G., S. Emselle, and R. F. Bishop. 2008. Changes in macromolecular transport appear early in Caco-2 cells infected with a human rotavirus. Scand. J. Gastroenterol. 43:314-322.

Centers for Disease Control and Prevention (CDC). 2008. Rotavirus surveillance-Worldwide, 2001-2008. MMWR Morb. Mortal. Wkly. Rep. 57:1255-1257.

Ciarlet, M., S. E. Crawford, and M. K. Estes. 2001. Differential infection of polarized epithelial cell lines by sialic acid-dependent and sialic acid-independent rotavirus strains. J. Virol. 75:1183411850 .

Dickman, K. G., S. J. Hempson, J. Anderson, S. Lippe, L. Zhao, R. Burakoff, and R. D. Shaw. 2000. Rotavirus alters paracellular permeability and energy metabolism in Caco-2 cells. Am. J. Physiol. Gastrointest. Liver Physiol. 279:G757-G766.

Ebina, T., M. Ohta, Y. Kanamaru, Y. Yamamoto-Osumi, and K. Baba. 1992. Passive immunizations of suckling mice and infants with bovine colostrum containing antibodies to human rotavirus. J. Med. Virol. 38:117-123.

Ebina, T., K. Tsukada, K. Umezu, M. Nose, K. Tsuda, H. Hatta, M. Kim, and T. Yamamoto. 1990. Gastroenteritis in suckling mice caused by human rotavirus can be prevented with egg yolk immunoglobulin (IgY) and treated with a protein-bound polysaccharide preparation (PSK). Microbiol. Immunol. 34:617-629.

Estes, M. K., and J. Cohen. 1989. Rotavirus gene structure and function. Microbiol. Rev. 53:410-449.

Guarino, A., A. Casola, E. Bruzzese, M. Saini, L. Nitsch, and A. Rubino. 1996. Human serum immunoglobulin counteracts rotaviral infection in Caco-2 cells. Pediatr. Res. 40:881-887.

Inagaki, M., M. Yamamoto, Xijier, Cairangzhuoma, K. Uchida, H. Yamaguchi, M. Kawasaki, K. Yamashita, T. Yabe, and Y. Kanamaru. 2010. In vitro and in vivo evaluation of the efficacy of bovine colostrum against human rotavirus infection. Biosci. Biotechnol. Biochem. 74:680-682. 
Laemmli, U. K. 1970. Cleavage of structural proteins during the assembly of the head of bacteriophage T4. Nature 227:680-685.

Minamoto, N., O. Sugimoto, M. Yokota, M. Tomita, H. Goto, M. Sugiyama, and T. Kinjo. 1993. Antigenic analysis of avian rotavirus VP6 using monoclonal antibodies. Arch. Virol. 131:293-305.

Murakami, K., S. Suzuki, N. Aoki, T. Okajima, D. Nadano, K. Uchida, K. Yamashita, T. Oka, K. Katayama, N. Takeda, and T. Matsuda. 2010. Binding of norovirus virus-like particles (VLPs) to human intestinal Caco-2 cells and the suppressive effect of pasteurized bovine colostrum on this VLP binding. Biosci. Biotechnol. Biochem. 74:541-547.

Nakagomi, T., and O. Nakagomi. 2009. A critical review on a globallylicensed, live, orally-administrable, monovalent human rotavirus vaccine: Rotarix. Expert Opin. Biol. Ther. 9:1073-1086.

Obert, G., I. Peiffer, and A. L. Servin. 2000. Rotavirus-induced structural and functional alterations in tight junctions of polarized intestinal Caco-2 cell monolayers. J. Virol. 74:4645-4651.

Sarker, S. A., T. H. Casswall, D. Mahalanabis, N. H. Alam, M. J. Albert, H. Brüssow, G. J. Fuchs, and L. Hammerström. 1998. Successful treatment of rotavirus diarrhea in children with immuno- globulin from immunized bovine colostrum. Pediatr. Infect. Dis J. 17:1149-1154

Svensson, L., B. B. Finlay, D. Bass, C. H. von Bonsdorff, and H. B. Greenberg. 1991. Symmetric infection of rotavirus on polarized human intestinal epithelial (Caco-2) cells. J. Virol. 65:4190-4197. Takahashi, K., K. Ohashi, Y. Abe, S. Mori, K. Taniguchi, T. Ebina, O. Nakagomi, M. Terada, and S. Shigeta. 2002. Protective efficacy of a sulfated sialyl lipid (NMSO3) against human rotavirus-induced diarrhea in a mouse model. Antimicrob. Agents Chemother. 46:420-424.

Uchida, K., N. Hiruta, H. Yamaguchi, K. Yamashita, K. Fujimura, and H. Yasui. 2012. Augmentation of cellular immunity and protection against influenza virus infection by bovine late colostrum in mice. Nutrition 28:442-446.

Uchida, K., H. Yamaguchi, M. Kawasaki, K. Yamashita, and N. Kaji. 2010. Bovine late colostrum (colostrum 6 or 7 days after parturition) supplement reduces symptoms of upper respiratory tract infection in infant. J. Jpn. Soc. Clin. Nutr. 31:122-127. 